\title{
CLINICAL ASPECTS AND MAIN DIAGNOSTIC METHODS OF CHEDIAK-HIGASHI SYNDROME
}

\author{
Poliana Paula de Oliveira ${ }^{1}$, Vilma Clemi Colli ${ }^{1}$
}

Clin Biomed Res. 2021;41(4):362-367

1 Centro Universitário Católico Salesiano Auxilium. Araçatuba, SP, Brasil.

Corresponding author:

Poliana Paula de Oliveira poliana_paula16@hotmail.com Centro Universitário Católico Salesiano Auxilium

Rod. Teotônio Vilela, 3821

16016-500, Araçatuba, SP, Brasil.

\section{ABSTRACT}

Chediak-Higashi syndrome is a disorder caused by a mutation in the LYST gene and characterized by immunodeficiency, oculocutaneous albinism, and neurological dysfunction resulting from changes in neutrophils. Homozygotes die in the first decade of life. The study is a literature review from different sources. We extracted articles published between 2000 and 2018 from SciELO, LILACS, MEDLINE (via PubMed), and Google Scholar databases. Our main objective was to report pathophysiology, clinical presentation, and the most common diagnostic methods. The syndrome affects the hematological and neurological systems, and laboratory diagnosis is first made by the presence of giant granules in leukocytes, mainly neutrophils in peripheral blood and bone marrow. A definitive diagnosis is made by cytochemical reaction (myeloperoxidase) and detection of mutation by molecular methods.

Keywords: Chediak; Differential diagnosis; Cytoplasmic granules; Higashi; Neutrophils

\section{INTRODUCTION}

Chediak-Higashi syndrome (CHS) is a disorder clinically characterized by oculocutaneous albinism, silver hair, photophobia ${ }^{1}$, immune system irregularities that predispose people to recurrent infections, hemorrhagic diathesis, and progressive neurological deterioration ${ }^{2,3}$. It is a rare condition with unknown incidence and prevalence ${ }^{4}$. CHS occurs as a result of a genetic mutation with autosomal recessive inheritance ${ }^{5}$. It manifests not only in humans but also in mice and other mammals, such as cats and whales $\mathrm{s}^{6,7}$.

CHS symptoms are clear, occurring soon after birth or in the course of childhood, in children under 5 years of age ${ }^{8,9}$, as a result of changes in the function of neutrophils, natural killer (NK) cells, platelets, and melanocytes ${ }^{5}$. It is a multisystem disease in which severe immunological defects are present mainly in neutrophils ${ }^{10}-$, which allows the classification of the disease as primary immunodeficiency ${ }^{11}$.

In 1943, Beguez-Cesar described the first case in 3 siblings who had as clinical characteristics abnormal granules in leukocytes and neutropenia. In 1952 and 1954, Chediak - a Cuban hematologist - and Higashi - a Japanese pediatrician - reported new cases, in which they described irregular distribution of myeloperoxidase (MPO) in neutrophil granules ${ }^{4}$ reason why the condition was named after them ${ }^{5}$.

Due to the severity and unfavorable prognosis of the disease, the affected person usually dies within the first decade of life. Death commonly results from hemophagocytic lymphohistiocytosis $(\mathrm{HLH})^{2}$, which corresponds to the accelerated phase of the disease and affects about $85 \%$ of cases, being generally fatal ${ }^{1,12}$, from infections ${ }^{2}$, which predominantly affect the respiratory tract, gastrointestinal tract, and $\mathrm{skin}^{8}$, with their etiology including Staphylococcus aureus and beta-hemolytic Streptococcus ${ }^{3,4}$, and from bleeding ${ }^{2}$. The diagnosis is often established at 5 years of age $\mathrm{e}^{5,11}$, but it is possible to confirm it during the prenatal period ${ }^{12}$.

$\mathrm{CHS}$ has a low frequency in Black people and a higher occurrence rate in children of consanguineous parents ${ }^{11}$. By the year 2017, there were fewer 
than 500 known reports around the world ${ }^{3}$. In India, only 5 cases were reported until $2000^{8}$, while in China, about 50 cases were reported until $2017^{3}$. In a study conducted in Japan from 2000 to 2010 , 15 patients were diagnosed with CHS, indicating that 1 or 2 individuals were diagnosed per year in the country 4

The treatment of choice for $\mathrm{CHS}$ is allogeneic bone marrow transplant (BMT), which, although effective at resolving hematological and immunological problems, is unable to alleviate and resolve neurological changes ${ }^{11-14}$. The procedure is considered to be curative and must be performed in the early stage of the disease, when it is still stable ${ }^{5,8,11}$. While awaiting BMT, treatment is aimed at processes resulting from failure of neutrophil function, such as infections and their symptoms. In general, paracetamol is used for fever and amoxicillin to fight infection ${ }^{15}$.

Studies and reports on the subject are still insufficient in the scientific community, which prevents or delays the diagnosis on many occasions. Studies on CHS are necessary to develop new approaches and therapies for patients, being posteriorly corrected and validated. The present study aimed to report pathological aspects, clinical profile, and main diagnostic methods related to $\mathrm{CHS}$.

\section{MATERIAL AND METHODS}

We conducted an exploratory study in the form of a literature review. We collected data between January and September 2019 from the following online databases: SciELO (Scientific Electronic Library Online), LILACS (Latin American and Caribbean Health Sciences Literature), MEDLINE (via PubMed), and Google Scholar. We used the following keywords: "Chediak-Higashi syndrome", "oculocutaneous albinism", "diagnosis", "neutrophils", "natural killer cells", and "cytoplasmic granules".

We searched for articles published between 2000 and 2018 in English or Portuguese. Thus, we included in the study 4 scientific articles in Portuguese and 25 in English, in addition to 3 books in Portuguese related to the hematology field, published in 2006 and 2013.

\section{PATHOLOGICAL ASPECTS AND CLINICAL PROFILE}

CHS has clinical characteristics related to the hematological, immunological, and neurological systems ${ }^{15}$. Patients may experience prolonged bleeding, bruising, and petechiae, since platelets have abnormal dense bodies - which contain serotonin, adenosine triphosphate, adenosine diphosphate, pyrophosphate, and calcium - although they may be in an appropriate number. Polymorphonuclear leukocytes and macrophages show reduced chemotaxis and delayed fusion of phagosomes with lysosomes ${ }^{13}$. As for neutrophils, there is a decrease in deformability and poor mobilization of bone marrow, with neutropenia ${ }^{8,15}$. Both NK cells ${ }^{15}$ and B cells have their function reduced ${ }^{6}$. T cells have defective cytotoxic activity ${ }^{13,16}$ attributable to the inability to secrete granules containing perforin and granzyme ${ }^{6}$, and there is a delay in processing and presenting antigens to lymphocytes ${ }^{6,13}$. These events weaken the bactericidal activity of defense cells. Therefore, infections are frequent, mainly bacterial and fungal infections, but they can also be cutaneous or systemic ${ }^{15}$.

Most patients develop the accelerated phase of $\mathrm{CHS}^{9,13}$, in which $\mathrm{HLH}$ is characterized by nonmalignant lymphohistiocytic infiltration of multiple organs, such as liver, spleen, and bone marrow ${ }^{15}$. Similar to lymphoma, this phase is promoted by viral infections, with emphasis on the Epstein-Barr virus ${ }^{8}$, leading to pancytopenia, thrombocytopenia, coagulopathy, neutropenia, jaundice, anemia, hepatosplenomegaly, and lymphadenopathy, which can result in multiple organ failure ${ }^{5,12}$. In $\mathrm{HLH}$, there is generalized inflammatory reaction, with intense activation of cytotoxic $T$ lymphocytes and macrophages and subsequent release of pro-inflammatory cytokines, such as tumor necrosis factor-alpha, gamma interferon, and interleukins. The action of these cytokines causes the phagocytosis of hematopoietic cells by macrophages (hemophagocytosis), reduced hematopoiesis, and increased cytopenia ${ }^{5,17,18}$.

The classic form of CHS poses a major risk of developing the accelerated phase, which is more commonly observed in children. The late form affects mainly adolescents and adults, being less aggressive and having few infection events. However, in these patients, neurological deterioration is more evident $t^{5,15,19}$ and associated with sensory and motor neuropathy, ataxia, cognitive impairment, tremor, convulsions, and parkinsonism, among other possible manifestations $\mathbf{s}^{3,20,21}$.

CHS has a phenotype described as partial albinism, with varying degrees of hypopigmentation of the skin, hair, and eyes ${ }^{20,22}$, thus being referred to as "silvery hair syndrome"22. Although melanocytes produce melanin, this pigment is stored in melanosomes, which are larger in CHS - therefore, pigmentary changes are believed to occur as a result of mutations that regulate the transport of intracellular organelles, leading to an inefficient transfer of melanosomes to keratinocytes, thus preventing the release of melanin ${ }^{13,22}$. Nevertheless, the literature has described unusual cases of hyperpigmentation in areas exposed to sunlight ${ }^{9,16,22,23}$. 
Skin color may vary from milky white to slate gray, with hypopigmentation being a risk factor for greater occurrence of sun damage ${ }^{20,22}$. The hair has a silver characteristic or metallic sheen, and its color may be white or gray - the same occurs with eyelashes and eyebrows ${ }^{3,20,22}$. Hypopigmentation of the eyes can cause photophobia, nystagmus, strabismus, and reduced visual acuity ${ }^{13,20,22}$.

\section{PATHOPHYSIOLOGY AND DIAGNOSIS}

The most common method for the presumptive diagnosis of $\mathrm{CHS}$ in clinical practice is hematoscopy. Cytoplasmic injury occurs with uncontrolled fusion of lysosomes or primary leukocyte granulations and phagocytosis. This event enables the presence of lysosomal inclusion bodies in several cell types ${ }^{1,24,25}$, with the formation of large granules ${ }^{26,27}$ and disturbance of lysosomal function ${ }^{4}$.

These typical granules can be observed in the cells by staining the leukocytes with Leishman stain or other panoptic stains (May-Grunwald-Giemsa and Wright staining). Cytochemical reactions are also important, such as the staining of MPO, an oxidative enzyme that is fundamental in the microbial death process and is part of the primary granulations (azurophilic or nonspecific) of neutrophils, thus becoming a marker of the myeloid pathway. This enzyme, when present in the cell, can be seen as a dark reddish hue, which is indicative of positivity, an event that occurs in $\mathrm{CHS}^{26-28}$. Secondary (specific) granulations do not show changes under microscopy. Granulations are generally unique in lymphocytes, but they tend to be multiple in monocytes ${ }^{26}$. Therefore, lysosomes are grossly enlarged (Figure 1) and can be seen by cytology as giant azurophilic granules in the cytoplasm, being peroxidase-positive $e^{4,5,12}$ and coalescent, which is pathognomonic of $\mathrm{CHS}$ when found in the analysis of peripheral blood and bone marrow ${ }^{4,5}$.

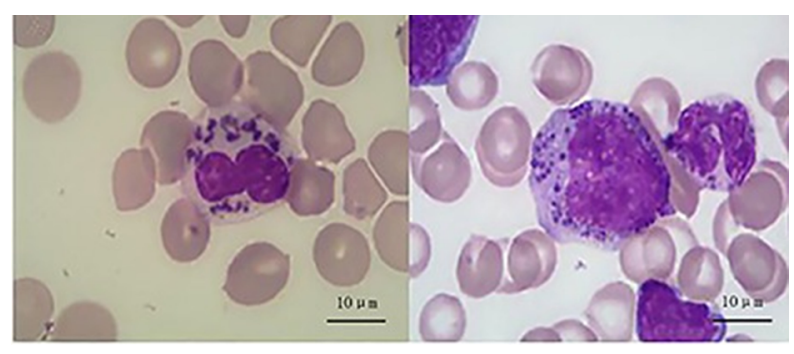

Figure 1: Peripheral blood smear (on the left) and bone marrow aspirate (on the right) showing giant intracytoplasmic granules in leukocytes and their precursors.

Source: Adapted from Wu et al. ${ }^{3}$
Lymphohistiocytic aggregates may be present in the skin and liver biopsies ${ }^{1}$. In addition, skin biopsy is important because it reveals the presence of giant melanosomes, with sparse coarse melanin pigment ${ }^{1,12}$, as shown in Figure 2.

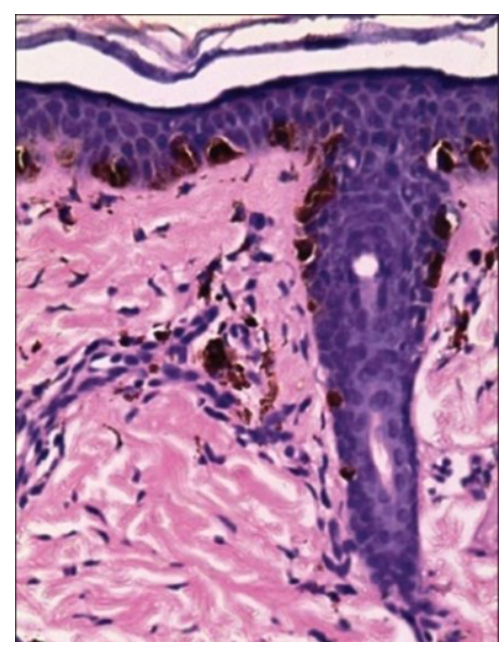

Figure 2: Skin biopsy showing coarse melanin pigment in the epidermis.

Source: Adapted from Raghuveer et al. ${ }^{9}$

The abnormalities that occur in CHS are observed mainly in neutrophils, NK cells, and melanocytes ${ }^{5}$, predominating in the myeloid pathway in relation to the lymphoid pathway, although they are also noticed in lymphocytes, hepatocytes, fibroblasts, renal tubular cells, endothelial cells, hematopoietic cells, platelets, pancreas, and neural and thyroid tissue $e^{4,8,12,16}$. These morphological (and consequently metabolic) changes might lead to pancytopenia, neutropenia, reduced hemoglobin levels, coagulogram changes, reduced fibrinogen, and elevated levels of bilirubin, transaminases, triglycerides, ferritin, and C-reactive protein $^{3-5,8,11,24}$.

During the prenatal period, CHS can be diagnosed by light microscopy based on the presence of pigment granules in the fetal hair shaft, grouped and in larger size ${ }^{12}$, in contrast to the normal pattern of fine and diffuse pigmentation ${ }^{4,12}$ (Figure 3). It can also be diagnosed by the observation of characteristic CHS cells in chorionic villus cell culture $^{7}$ and of leukocytes with granular changes in fetal blood samples ${ }^{8,9}$. 


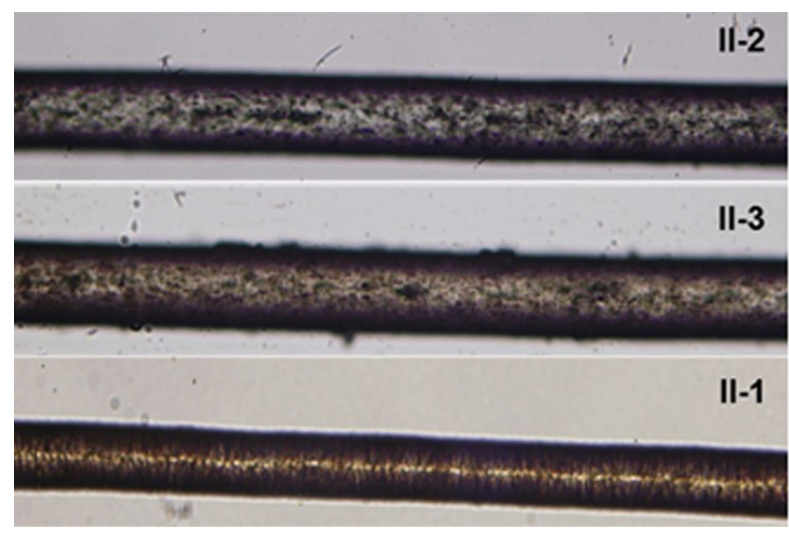

Figure 3: Light microscopy of the hair strand showing irregular, coarse melanin granules in patients (II-2 and II-3), as opposed to the normal uniform distribution pattern (II-1). Source: Adapted from Jin et al. ${ }^{29}$

A definitive diagnosis is made mostly by gene analysis ${ }^{29}$. The genetic mutation that causes $\mathrm{CHS}$ was identified in 1996 in the LYST gene, located on chromosome 1 (1q42-44) ${ }^{3}$, which has 55 exons and encodes the protein in charge of lysosomal transport (CHS1), which comprises 3801 amino acids, with a molecular weight of $430 \mathrm{kDa}$, and is scarce in individuals with the syndrome ${ }^{8,24}$. The exact function of CHS1 is unclear, but it is known to be a cytosolic protein ${ }^{6}$ responsible for the synthesis, transport, and fusion of cytoplasmic vesicles, thus inhibiting the incorporation of proteins into the lysosomal membrane ${ }^{3-5}$.

Because the LYST gene is the only one currently associated with $\mathrm{CHS}$, molecular studies - such as DNA sequencing - are vital to identifying genetic mutations, in order to confirm the diagnosis and even to establish the prognosis of the disease ${ }^{10,29}$. Although a molecular diagnosis is more complex, due to the size of the gene ${ }^{10}, 40$ mutations have already been identified throughout the process, which can be of the missense and nonsense type, deletions, or insertions ${ }^{24}$. Molecular genotype correlates with clinical phenotype so that missense mutations reveal a less aggressive presentation and neurological involvement that progresses slowly without the occurrence of $\mathrm{HLH}$, whereas deletions in the LYST gene are associated with severe $\mathrm{CHS}$, fatal infections, and $\mathrm{HLH}^{1,4,30}$.

Differential diagnoses include Griscelli syndrome, Hermansky-Pudlak syndrome, and Elejalde syndrome ${ }^{1,3,16,29}$, as these conditions manifest in the form of ocular and cutaneous albinism, immune dysfunction, and neurological impairment, among other common manifestations $\mathrm{s}^{1,8}$. We can distinguish $\mathrm{CHS}$ from them mainly by the analysis of peripheral blood smear, where the characteristic giant intracytoplasmic granules are found in leukocytes - what does not occur for the other diseases. Molecular tests, skin biopsy, and microscopic examination of hair are also important in the diagnosis $8,10,16,29$.

Some cases of acute myeloid leukemia and, less frequently, of chronic myeloid leukemia as well as myelodysplastic syndromes may be diagnosed as pseudo-Chediak-Higashi anomaly. These conditions present with granules in leukemic blast cells, promyelocytes, and myelocytes similar to those found in CHS, known as pseudo-ChediakHigashi granules, which are also positive for MPO, with variable positivity for periodic acid-Schiff staining ${ }^{16,31,32}$.

An accurate observation and description of cytoplasmic granules is essential, since numerous diseases may have this feature. Severe infectious processes may occur due to toxic granulation of neutrophils, but this will end once the infection is resolved. The same does not occur with $\mathrm{CHS}$ granules, which will remain at any stage of the disease; in addition, they can be distinguished by their larger size. Other diseases, such as MayHegglin anomaly and Alder-Reilly anomaly, also present with leukocyte inclusions, which reinforces the need for differential diagnosis ${ }^{11}$.

\section{CONCLUSION}

$\mathrm{CHS}$ is a disease characterized by severe immunodeficiency caused by a failure in the metabolism of cells such as neutrophils. Clinically, the most common manifestations include oculocutaneous albinism, frequent infections, and neurological dysfunction, with several changes in blood count parameters. A presumptive diagnosis is made by the presence of coalescent granules of lysosomes in neutrophils and other cell types, whereas a definitive diagnosis requires molecular methods to identify mutations in the LYST gene.

\section{Acknowledgements}

We are grateful to Denise Junqueira Matos for her critical review of the manuscript. 


\section{REFERENCES}

1. Roy A, Kar R, Basu D, Srivani S, Badhe BA. Clinico-hematological profile of Chediak-Higashi syndrome: experience from a tertiary care center in south India. Indian J Pathol Microbiol. 2011;54(3):547-51.

2. Gil-Krzewska A, Wood SM, Murakami Y, Nguyen V, Chiang SCC, Cullinane AR, et al. ChediakHigashi syndrome: Lysosomal trafficking regulator domains regulate exocytosis of lytic granules but not cytokine secretion by natural killer cells. J Allergy Clin Immunol. 2016;137(4):1165-77.

3. Wu XL, Zhao XQ, Zhang BX, Xuan F, Guo HM, Ma FT. A novel frameshift mutation of Chediak-Higashi syndrome and treatment in the accelerated phase. Braz J Med Biol Res. 2017;50(4):e5727.

4. Maaloul I, Talmoudi J, Chabchoub I, Ayadi L, Kamoun TH, Boudawara T, et al. Chediak-Higashi syndrome presenting in accelerated phase: A case report and literature review. Hematol Oncol Stem Cell Ther. 2016;9(2):71-5.

5. Mendes A, Cartaxo CGB. Síndrome de Chediak-Higashi em fase acelerada: um relato de caso. Arq Asma Alerg Imunol. 2018;2(2):275-8.

6. Ward DM, Griffiths GM, Stinchcombe JC, Kaplan J. Analysis of the Lysosomal Storage Disease Chediak-Higashi Syndrome. Traffic. 2000;1(11):816-22.

7. Reddy RR, Babu BM, Venkateshwaramma B, Hymavathi $\mathrm{CH}$. Silvery hair syndrome in two cousins: Chediak-Higashi syndrome vs Griscelli syndrome, with rare associations. Int $J$ Trichology. 2011;3(2):107-11.

8. Patne SCU, Kumar S, Bagri NK, Kumar A, Shukla J. ChédiakHigashi Syndrome: A Case Report. Indian J Hematol Blood Transfus. 2013;29(2):80-3.

9. Raghuveer C, Murthy SC, Mithuna MN, Suresh T. Silvery Hair with Speckled Dyspigmentation: Chediak-Higashi Syndrome in Three Indian Siblings. Int J Trichology. 2015;7(3):133-5.

10. Singh A, Bryan MM, Roney JC, Cullinane AR, Gahl WA, Khurana N, et al. A clinical report of
Chediak-Higashi syndrome in infancy with a novel genotype from the Indian subcontinent. Int J Dermatol. 2016;55(3):317-21.

11. Carlos JLA, Oliveira MV, Souza CL. Chediak-Higashi syndrome: case report in afro-descendant individual. J Bras Patol Med Lab. 2014;50(3):205-9.

12. Fantinato GT, Cestari SCP, Afonso JPJM, Sousa LS Enokihara MMSS. Você conhece esta síndrome? An Bras Dermatol. 2011;86(5):1029-38.

13. Shiflett SL, Kaplan J, Ward DM. Chediak-Higashi Syndrome: A Rare Disorder of Lysosomes and Lysosome Related Organelles. Pigment Cell Res. 2002;15(4):251-7.

14. Faber IV, Prota JRM, Martinez ARM, Nucci A, Lopes-Cendes I, França MC Jr. Inflammatory demyelinating neuropathy heralding accelerated chediakhigashi syndrome. Muscle Nerve. 2017;55(5):756-60.

15. Rajeev S, Prakash KS, Ruchi A, Sonia C, Kundan M. ChediakHigashi Syndrome Presented as Accelerated Phase in a 3 Year Girl Child: Case Report of a Rare Entity. J Clin Case Rep. 2013;3(6):1000275.

16. Pujani M, Agarwal K, Bansal S, Ahmad I, Puri V, Verma D, et al. Chediak-Higashi syndrome a report of two cases with unusual hyperpigmentation of the face. Turk Patoloji Derg. 2011;27(3):246-8.

17. Reis PC, Almeida S, Behrens E. Uma Nova Era no Diagnóstico e Tratamento da Síndrome Hemofagocítica. Acta Pediatr Port. 2016;47:333-44.

18. Jobim M, Trotta E, Pilcher O, Fernandes FB, Daut L, Jobim LF. Linfo-histiocitose hemofagocítica: tratamento com plasmaferese e gamaglobulina endovenosa. Rev AMRIGS. 2010;54(1):72-6.

19. Helmi MM, Saleh M, Yacop B, ELSawy D. Chédiak-Higashi syndrome with novel gene mutation. BMJ Case Rep. 2017;2017:bcr2016216628.
20. Dotta L, Parolini S, Prandini A Tabellini G, Antolini M, Kingsmore SF, et al. Clinical, laboratory and molecular signs of immunodeficiency in patients with partial oculo-cutaneous albinism. Orphanet J Rare Dis. 2013;8(1):168.

21. Islam ASMA, Hawsawi ZM, Islam MS, Ibrahim OAH. ChédiakHigashi Syndrome: An Accelerated Phase with Hereditary Elliptocytosis: Case Report and Review of the Literature. Ann Saudi Med. 2001;21(3-4):221-4.

22. Valente NYS, Machado MCMR, Boggio P, Alves ACF, Bergonse FN, Casella $\mathrm{E}$, et al. Polarized light microscopy of hair shafts aids in the differential diagnosis of ChédiakHigashi and Griscelli-Prunieras syndromes. Clinics. 2006; 61(4):327-32.

23. Chandravathi PL, Karani HD, Siddaiahgari SR, Lingappa L. Light Microscopy and Polarized Microscopy: A Dermatological Tool to Diagnose Gray Hair Syndromes. Int J Trichology. 2017;9(1):38-41.

24. Rudramurthy $P$, Lokanatha $\mathrm{H}$. Chediak-Higashi syndrome: A case series from Karnataka, India. Indian J Dermatol. 2015;60(5):524.

25. Bharti S, Bhatia P, Bansal D, Varma N. The Accelerated Phase of Chediak-Higashi Syndrome: The Importance of Hematological Evaluation. Turk J Haematol. 2013;30(1):85-7.

26. Lorenzi TF. Manual de Hematologia: Propedêutica e Clínica. 4a ed. Rio de Janeiro: Guanabara Koogan; 2013.

27. Lorenzi TF, coordenadora. Atlas de Hematologia: clínica hematológica ilustrada. Rio de Janeiro: Guanabara Koogan; 2006.

28. Santos PCJL, coordenador; Silva AM, Neto LMR, organizadores. Hematologia: métodos e interpretação. São Paulo: Roca; 2013. (Análises Clínicas e Toxicológicas; vol 1).

29. Jin $Y$, Zhang L, Wang $S$, Chen F, Gu Y, Hong E, et al. Whole Genome Sequencing Identifies Novel Compound Heterozygous Lysosomal Trafficking Regulator Gene Mutations 
Associated with Autosomal Recessive Chediak-Higashi Syndrome. Sci Rep. 2017;7(1):41308.

30. Westbroek W, Adams D, Huizing M, Koshoffer A, Dorward $\mathrm{H}$, Tinloy B, et al. Cellular Defects in Chediak-Higashi Syndrome Correlate with the Molecular Genotype and Clinical Phenotype. J Invest Dermatol. 2007;127(11):2674-7.

31. Avcı Z, Malbora B, Özbek N. Pseudo Chediak-Higashi Anomaly. Turk J Haematol. 2013;30(2):230-1.
32. Agrawal $P$, Kumar N, Sharma $P$, Varma S, Varma N. Pseudo Chediak-Higashi Granules in Acute Lymphoblastic Leukemia: A Rare Entity. Indian J Hematol Blood Transfus. 2014;30(3):201-3.

Received: Set 24, 2020 Accepted: Jul 13, 2021 